\title{
Some insight on the structure/activity relationship of metal nanoparticles in $\mathrm{Cu} / \mathrm{SiO}_{2}$ catalysts
}

\author{
Nicola Scotti a Elisabetta Finocchio ${ }^{\text {b }}$, Claudio Evangelisti a, Marcello Marelli a, Rinaldo Psaro ${ }^{a}$, \\ Nicoletta Ravasio a, , Federica Zaccheria a \\ a The Institute of Molecular Science and Technologies (ISTM), CNR Research Centres, LabCat, via C. Golgi 19, 20133 Milano, Italy \\ b Dip. Ingegneria Civile, Chimica e Ambientale (DICCA), Scuola Politecnica, Università di Genova, Via all'Opera Pia 15, 16145 Genova, Italy
}

\section{A R T I C L E I N F O}

\section{Article history:}

Received 28 March 2019

Accepted 8 May 2019

Published 5 November 2019

\section{Keywords:}

Cu catalysts

Metal particle morphology

Lewis acid sites

Hydrogenation

Bifunctional catalysts

\begin{abstract}
A B S T R A C T
The activity of two $\mathrm{Cu} / \mathrm{SiO}_{2}$ catalysts prepared by the chemisorption hydrolysis technique has been tested in the hydrogenation reaction of 3-methyl-cyclohexanone. Both catalysts were found to be very active at $60{ }^{\circ} \mathrm{C}$ and $1 \mathrm{~atm}$ of $\mathrm{H}_{2}$. Characterization of the materials by FT-IR of adsorbed CO and TEM put in light the presence of well formed $\mathrm{Cu}$ cristallites. By assuming a cuboctahedral model we could show that the hydrogenation activity is linked to high coordination sites on the metal particle. A comparison is also reported with a sample prepared by ammonia evaporation that was found to be inactive in the hydrogenation reaction under the same experimental conditions.
\end{abstract}

(C) 2019, Dalian Institute of Chemical Physics, Chinese Academy of Sciences. Published by Elsevier B.V. All rights reserved.

\section{Introduction}

Copper catalysts are among the most used heterogeneous catalysts in the chemical industry. In particular $\mathrm{Cu}$ chromites are used in hydrogenation and dehydrogenation reactions while $\mathrm{Cu} / \mathrm{Zn} / \mathrm{Al}$ systems are the catalysts of choice for the synthesis of methanol [1]. For these catalysts the nature of the active species of copper has been the center of debate for many years, focussing mainly on the role of $\mathrm{Cu}(0)$ and $\mathrm{Cu}(\mathrm{I})$. In general it was accepted that $\mathrm{Cu}(\mathrm{I})$ is involved in the active site in copper chromite catalyzed hydrogenations while the role of $\mathrm{Cr}$ is to stabilize it from being reduced [2] although more recently the role of reduced metallic $\mathrm{Cu}$ has been recognized [3]. Monovalent copper sites are significantly more active than the sites of metallic copper also in cyclohexanol dehydrogenation over $\mathrm{Cu} / \mathrm{Zn}, \mathrm{Cu} / \mathrm{Mg}$ [4] and $\mathrm{Cu} / \mathrm{Al}_{2} \mathrm{O}_{3}$ systems [5].
On the other hand, there are several parameters that influence the activity of a metallic catalyst beside the oxidation state. Among them, the role of metal particle morphology has often been understimated whereas a lot of attention has been devoted to metal support interactions and to the support itself.

Surface atoms are composed of face atoms, edge atoms and corner atoms. Face (terrace) atoms are also called high-coordination-number atoms, on the other hand edge and corner represent the low-coordination number atoms, since they are the most defective sites on the surface. Geometry and coordination number of the surface atoms reflect by weight on their electronic, thus catalytic, properties.

When particle size becomes very small, catalytic reactions can show a significant change in turnover frequency. In this case the reaction, according to Boudart definition, [6] is structure-sensitive. Acetone hydrogenation over a series of $\mathrm{Cu} / \mathrm{SiO}_{2}$

\footnotetext{
* Corresponding author. E-mail: n.ravasio@istm.cnr.it

DOI: S1872-2067(19)63392-9 | http://www.sciencedirect.com/science/journal/18722067 | Chin. J. Catal., Vol. 40, No. 11, November 2019
} 
catalysts at $150{ }^{\circ} \mathrm{C}$ and $1 \mathrm{~atm}$ of $\mathrm{H}_{2}$, has shown to be structure sensitive. Thus, by comparing 3 catalysts with different $\mathrm{Cu}$ loadings the TOF was found to increase very much with the $\mathrm{Cu}$ particle size, varying from $0.056 \mathrm{~s}^{-1}$ on the most highly dispersed $\mathrm{Cu}$ catalyst $\left(0.5 \% \mathrm{Cu}, d_{\mathrm{m}}=1.5 \mathrm{~nm}\right)$ to $0.17 \mathrm{~s}^{-1}$ on the $5 \%$ Cu material $\left(d_{\mathrm{m}}=14 \mathrm{~nm}\right)$ to $2.4 \mathrm{~s}^{-1}$ occurring on $110 \mathrm{~nm}$ crystallites, due to modification of electronic properties of the particle itself [7]. Similar results were also obtained by comparing a $\mathrm{Cu} / \mathrm{Al}_{2} \mathrm{O}_{3}$ catalyst with $\mathrm{Cu} / \mathrm{Cr}_{2} \mathrm{O}_{3}$. In this case, the former with an average particle size of $3 \mathrm{~nm}$ was found to be 6 times less active than the latter with a mean particle size of $23 \mathrm{~nm}$ [8].

Also for methanol synthesis over $\mathrm{Cu}$ and $\mathrm{Cu} / \mathrm{Zn}$ catalysts TOF decreased for copper particle sizes below about $8 \mathrm{~nm}$ [9] by a factor of about 3 going from particles of 8 to $2 \mathrm{~nm}$. In this case the copper particle size effect is due to the increase in the fraction of atoms with lower coordination numbers below 8 $\mathrm{nm}$. Thus, methanol synthesis reaction predominantly takes place at step-edge sites like $\mathrm{Cu}$ [211] facets, that small particle are not able to accommodate.

Research on $\mathrm{Cu} / \mathrm{SiO}_{2}$ systems in the last decade has increased continuously due to the interest in finding non-noble and non-Cr based catalysts for the very many hydrogenation steps in the pathway from cellulose or hemicellulose to fuel and chemicals. $[10,11]$ Moreover $\mathrm{Cu} / \mathrm{SiO}_{2}$ systems show high activity in the hydrogenation of dimethyloxalate to ethylene glycol, a reaction of relevant interest since DMO can be obtained from syngas [12].

Here we wish to shed some light on role of different sites on the metal particle obtained by the $\mathrm{CH}$ method. A comparison is also made with catalysts prepared starting from the same precursor, namely a $\mathrm{Cu}\left[\left(\mathrm{NH}_{3}\right)_{4}\right]^{2+}$ solution, but with a different method, namely Ammonia Evaporation.

\section{Experimental}

\subsection{Catalyst preparation}

Silica A (BET $=460 \mathrm{~m}^{2} / \mathrm{g}, \mathrm{PV}=0.74 \mathrm{ml} / \mathrm{g}$ ) was obtained from Sigma-Aldrich, silica B (BET $=267 \mathrm{~m}^{2} / \mathrm{g}, \mathrm{PV}=1.65 \mathrm{ml} / \mathrm{g}$ ) from Evonik (Aeroperl 300/30).

Catalysts were prepared by chemisorption-hydrolysis method by adding the support to a solution containing $\mathrm{Cu}\left[\left(\mathrm{NH}_{3}\right)_{4}\right]^{2+}$ prepared by dropping aqueous $\mathrm{NH}_{3}$ to a $\mathrm{Cu}\left(\mathrm{NO}_{3}\right)_{2} \cdot 3 \mathrm{H}_{2} \mathrm{O}$ solution until $\mathrm{pH}=9$ had been reached. After 20 min under stirring, the slurry, held in an ice bath at $0{ }^{\circ} \mathrm{C}$, was diluted with water. The solid was separated by filtration with a Büchner funnel, washed with water, dried overnight at $120^{\circ} \mathrm{C}$, and calcined in air at $350{ }^{\circ} \mathrm{C}$ for $4 \mathrm{~h}$. Two samples with a nominal $\mathrm{Cu}$ loading of $8 \%$ (silica A) and 16\% (silica B) were obtained.

\subsection{Characterization}

High-resolution transmission electron microscopy (HRTEM) and high angular annular dark field scanning electron microscopy (HAADF-STEM) micrographs of copper catalysts were carried out with a ZEISS LIBRA 200FE (analytical transmission electron microscope) equipped with FEG source. Samples were gently crushed in an agate mortar, ultrasonically dispersed in isopropyl alcohol, and a drop of the suspension was deposited on a lacey carbon supported film on Cu TEM grids (300 mesh). Histograms of the particle size distribution were obtained by counting onto several TEM micrographs at least 500 particles, spanning over different grids area. The mean particle diameter $\left(d_{\mathrm{m}}\right)$ was calculated by using the formula $d_{\mathrm{m}}=\Sigma d_{\mathrm{i}} n_{\mathrm{i}} / \Sigma n_{\mathrm{i}}$ where $n_{\mathrm{i}}$ was the number of particles of diameter $\mathrm{d}_{\mathrm{i}}$.

Temperature-programmed reduction (TPR) analysis was performed with a modified version of the Pulse chemisorb 2700 apparatus from Micromeritics. Catalysts (samples containing ca. $2 \mathrm{mg}$ of $\mathrm{Cu}$ ) were diluted with quartz, calcined at 500 ${ }^{\circ} \mathrm{C}$ under $\mathrm{O}_{2}(40 \mathrm{~mL} / \mathrm{min})$, and then reduced at $8{ }^{\circ} \mathrm{C} / \mathrm{min}$ under a flow $\left(15 \mathrm{~mL} / \mathrm{min}\right.$ ) of a $8 \% \mathrm{H}_{2} /$ Ar mixture. The $\mathrm{H}_{2}$ consumption was detected by a thermal conductivity detector (TCD).

For Fourier transform infrared (FT-IR) studies (FT-IR Thermofisher Nexus instrument, 100 scans, OMNIC software), powdered catalysts have been pressed in self supporting disks (average weight $30 \mathrm{mg}$ ), reduced in pure hydrogen and outgassed at 270 and $500{ }^{\circ} \mathrm{C}$ directly in the IR cell connected to a conventional gas manipulation apparatus. $\mathrm{CO}$ adsorption was performed at liquid nitrogen temperature in the presence of 10 torr CO gas. FT-IR spectra have been recorded outgassing at increasing temperature in the range $-130{ }^{\circ} \mathrm{C} / \mathrm{room}$ temperature at decreasing CO coverage. Deconvolution spectra have been obtained using OMNIC software (type of band Gaussian-Lorentzian, no fixed baseline, range $2230-2080 \mathrm{~cm}^{-1}$ ).

\subsection{Catalytic tests}

In a typical reaction test, $100 \mathrm{mg}$ of the catalyst was pre-reduced in $\mathrm{H}_{2}(1 \mathrm{~atm})$ at $270{ }^{\circ} \mathrm{C}$ in a glass reactor. Next 100 $\mathrm{mg}$ of 3-methylcyclohexanone and $6 \mathrm{~mL}$ of n-heptane were added under $\mathrm{N}_{2}$ atmosphere, then $\mathrm{N}_{2}$ was removed under vacuum and substituted with $\mathrm{H}_{2}$. Reactions were carried out under atmospheric pressure and magnetic stirring (1000 rpm) at 60 ${ }^{\circ} \mathrm{C}$.

The products were analyzed by GC-MS and GC-FID (5\%-phenyl-methyl polysiloxane column) using an internal standard for the quantification. Conversion and selectivity were calculated on the basis of the following equation:

$$
\begin{aligned}
& C(\%)=\frac{\mathrm{mol}_{\text {conv }}}{\mathrm{mol}_{\text {tot }}} \cdot 100 \\
& S(\%)=\frac{\mathrm{mol}_{\text {prod }}}{\mathrm{mol}_{\text {conv }}} \cdot 100
\end{aligned}
$$

\subsection{Surface Composition of the Catalysts and TOF - Cubooctahedron Model}

Assuming that the catalyst nanoparticles are cubooctahedral in shape with a face-centered cubic $(f c c)$ structure, it is possible to calculate the number of different sites depending on the size of the nanocrystals $[13,14]$. The total number of atoms of a copper nanoparticle for a $f c c$ crystal (as is the case of copper) can be calculated from $d_{\mathrm{np}}=1.105 d_{\mathrm{at}} N_{\mathrm{T}^{1 / 3}}$, in which $d_{\mathrm{np}}$ is the average diameter of nanoparticles obtained by HRTEM and $d_{\text {at }}$ 
is the atom diameter of copper (2.56 $\AA$ ). The formula does not depend on particle shape.

Eq. (3) allows one to calculate $m$, the length of an edge expressed as an atom.

$$
N_{\mathrm{T}}=\left(10 \mathrm{~m}^{3}-15 \mathrm{~m}^{2}+11 \mathrm{~m}-3\right) / 3
$$

All of the following, including $N_{\mathrm{B}}$ (bulk atoms), $N_{\mathrm{S}}$ (surface atoms), $N_{\mathrm{HS}}$ (high coordination atoms), and $N_{\mathrm{LS}}$ (low coordination atoms), are given from Eqs. (4)-(7):

$$
\begin{gathered}
N_{\mathrm{B}}=16 m^{3}-63 m^{2}+84 m-38 \\
N_{\mathrm{S}}=10 m^{2}-20 m+12 \\
N_{\mathrm{HS}}=6(m-2)^{2}+4(m-3)(m-2) \\
\quad N_{\mathrm{LS}}=24(m-2)+12
\end{gathered}
$$

Turnover frequencies were calculated using the Eq. (8):

$$
\operatorname{TOF}_{x} \quad\left(\mathrm{~h}^{\wedge}(-1)\right)=n_{\text {conv }} /\left(t^{*} n_{\mathrm{x}}\right)
$$

Where $\mathrm{TOF}_{x}$ is the turnover frequency normalized for a specific site $\left(N_{\mathrm{S}}, N_{\mathrm{HL}}, N_{\mathrm{LS}}\right), n_{\text {conv }}$ are the converted moles of the reactant, $t$ is the time in hours and $n_{\mathrm{x}}$ are the moles of the specific atom site. The $n_{\mathrm{x}}$ values ( $n_{\mathrm{S}}, n_{\mathrm{HS}}, n_{\mathrm{LS}}$ ) were calculated multiplying the fraction of a specific site on a single particle $\left(N_{\mathrm{X}} / N_{\mathrm{T}}\right.$, where $N_{\mathrm{X}}=N_{\mathrm{S}}, N_{\mathrm{HL}}$ or $N_{\mathrm{LS}}$ ) for the total moles of copper $\left(\mathrm{n}_{\mathrm{Cu}}\right)$ present in the reaction (Eq. (9)):

$$
n_{\mathrm{x}}=n_{\mathrm{Cu}}{ }^{*} N_{\mathrm{x}} / N_{\mathrm{T}}
$$

\section{Results and discussion}

We have long been involved in the study of several reactions promoted by $\mathrm{Cu}$ catalysts prepared by the chemisorption hydrolysis (CH) method (Fig. 1). This method exploits the electrostatic interaction between the support and the solution of the precursor thus favouring high dispersion of the metallic phase and high hydrogenation activity, particularly when compared with catalysts prepared by incipient wetness, as we could show in the hydrogenation of 1,3-cyclooctadiene [15].

The particular morphology of the very small particle obtained by the $\mathrm{CH}$ method is also responsible of the acidic behaviour of pre-reduced $\mathrm{Cu} / \mathrm{SiO}_{2}$ catalyst in some particular conditions, e. $\mathrm{g}$ in the one pot transformation of GVL into valeric esters. Thus, by comparing the FTIR spectra of adsorbed pyridine on the catalyst before and after reduction, namely $\mathrm{CuO} / \mathrm{SiO}_{2}$ and $\mathrm{Cu} / \mathrm{SiO}_{2}$, we could show that not only Lewis acid sites are present on the surface of both materials, but also that they increase after the pre-reduction treatment [16].

The pre-reduced $\mathrm{Cu} / \mathrm{SiO}_{2}$ catalyst was tested in the one-pot transformation of $\gamma$-valerolactone into pentyl valerate and showed comparable activity (91\% vs 92\% conversion) and improved selectivity ( $92 \%$ vs $72 \%$ ) with respect to the previously reported copper catalyst supported on acidic material [17].

The Lewis acidity expressed by unreduced $\mathrm{CuO} / \mathrm{SiO}_{2}$ was ascribed to the defectivity of the highly dispersed $\mathrm{CuO}$ phase, shown to be in distorted octahedral configuration by means of

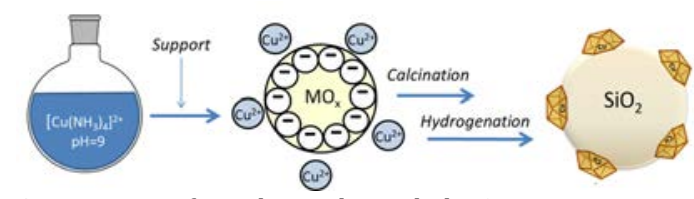

Fig. 1. Formation of metal particles with the $\mathrm{CH}$ preparation method.
EXAFS and DRUV spectroscopic analysis [18]. Reduction of copper oxide into well-formed cuboctahedron $\mathrm{Cu}(0)$ particles in a face cubic centered $(f c c)$ crystal structure as shown by TEM enhances even more this defectivity. Moreover, the comparison of turnover frequencies obtained for an $8 \% \mathrm{Cu} / \mathrm{SiO}_{2}-\mathrm{ZrO}_{2}$ and a $16 \% \mathrm{Cu} / \mathrm{SiO}_{2}$ catalysts with respect to total surface atoms, high coordination sites, and low coordination sites according to a cuboctrahedron model, as well as with respect to Lewis sites as evaluated from pyridine adsorption spectra put in light that the acidity of the catalyst in this particular reaction is linked with low coordination sites on the metal particle (Table 1).

Thus, the ratio between the two values calculated for low coordination sites (1.06) and for Lewis sites (1.04) are close to 1 . This unequivically shows that very small metal particles can exhibit catalytically relevant Lewis acidity and that this behaviour is linked to low coordination atoms.

However, we were never able to show the role of the different atoms in the isolated hydrogenation activity because most substrates give acid catalyzed side-products in the presence of $\mathrm{Cu} / \mathrm{SiO}_{2}$, particulalry deoxygenation ones [19].

In this paper we wish to report results obtained in the hydrogenation of 3-Me-cyclohexanone over two $\mathrm{Cu} / \mathrm{SiO}_{2}$ catalysts prepared by $\mathrm{CH}$, the first one on a mesoporous silica hereafter called $\mathrm{A}$, and the second one on a granulated fumed one hereafter called B to get some more insight into the features affecting catalytic activity.

A detailed characterization of the two catalysts was carried out by TEM techniques in order to investigate the structural features of the silica-supported copper catalysts (Fig. 2). HAADF-STEM micrographs at low magnifications pointed out a highly homogeneous dispersion of the copper phase within the silica grains in both samples $\left(\mathrm{Cu} / \mathrm{SiO}_{2} \mathrm{~A}\right.$ and $\left.\mathrm{Cu} / \mathrm{SiO}_{2} \mathrm{~B}\right)$. A narrow size distribution (ranging 2.0-6.0 nm) of copper nanoparticles was revealed, with a mean diameter of $3.4 \mathrm{~nm}$ for the porous silica and $2.4 \mathrm{~nm}$ for the fumed one (Figs. 2(A) and 2(C), respectively). Moreover, HR-TEM micrographs showed well-formed roundish particles in agreement with previously observed cuboctahedron copper particles supported on silica obtained by the same approach [16].

The adsorption of $\mathrm{CO}$ probe molecule on the reduced $\mathrm{Cu} / \mathrm{SiO}_{2} \mathrm{~A}$ catalysts was also studied. FT-IR spectra of adsorbed surface species were recorded starting from $\mathrm{CO}$ adsorption at

\section{Table 1}

Turnover frequencies evaluated after a $1 \mathrm{~h}$ reaction and calculated on both surface atoms and acidic sites [16].

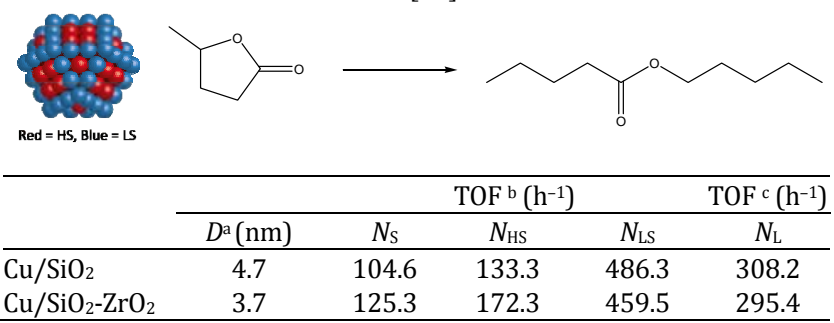

a Mean particle diameter evaluated by HRTEM; ${ }^{\mathrm{b}}$ TOF (after $1 \mathrm{~h}$ reaction) evaluated by using the surface atoms composition according to the cuboctahedral shape model reported by Kaneda [14]; c TOF (after $1 \mathrm{~h}$ reaction) evaluated on Lewis acidic sites $\mathrm{L}$. 


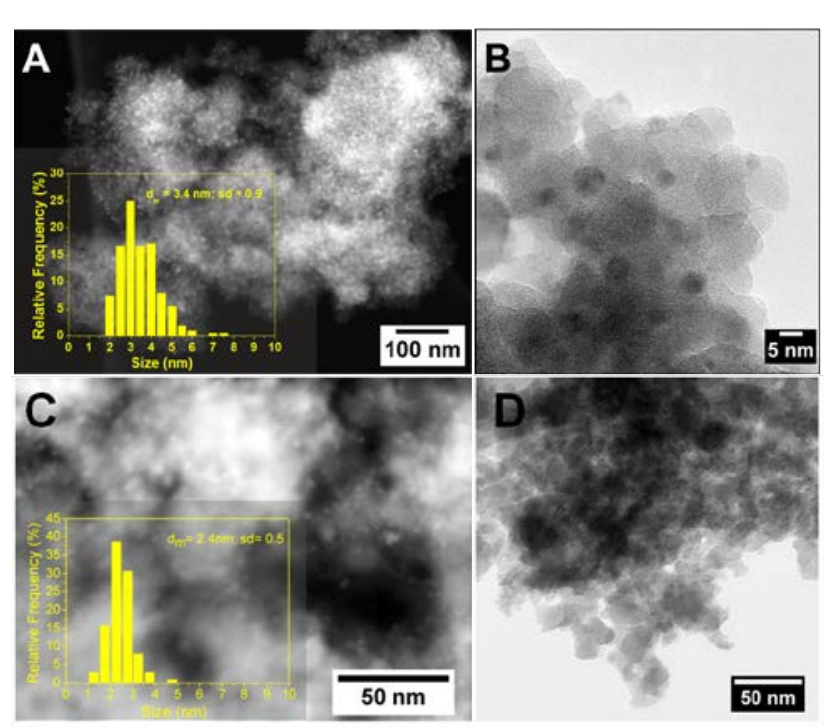

Fig. 2. Representative HAADF-STEM micrograph of a catalyst grain together with $\mathrm{Cu}$ particle size distribution (left side) and HRTEM micrograph (right side) of $\mathrm{CuO} / \mathrm{SiO}_{2} \mathrm{~A}(\mathrm{~A}, \mathrm{~B})$ and $\mathrm{CuO} / \mathrm{SiO}_{2} \mathrm{~B}(\mathrm{C}, \mathrm{D})$.

$-130{ }^{\circ} \mathrm{C}$ and following progressive warming upon outgassing until room temperature. In Fig. 3 spectra of the surface species arising from $\mathrm{CO}$ adsorption over the reduced $\mathrm{Cu} / \mathrm{SiO}_{2} \mathrm{~A}$ sample are reported (reduction temperatures 270 and $500{ }^{\circ} \mathrm{C}$ ).

At high CO coverage, under our experimental conditions Fig.

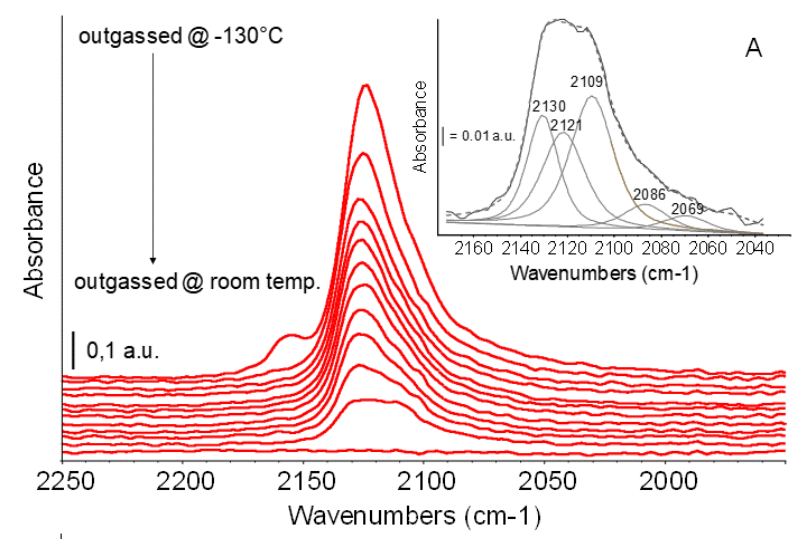

B

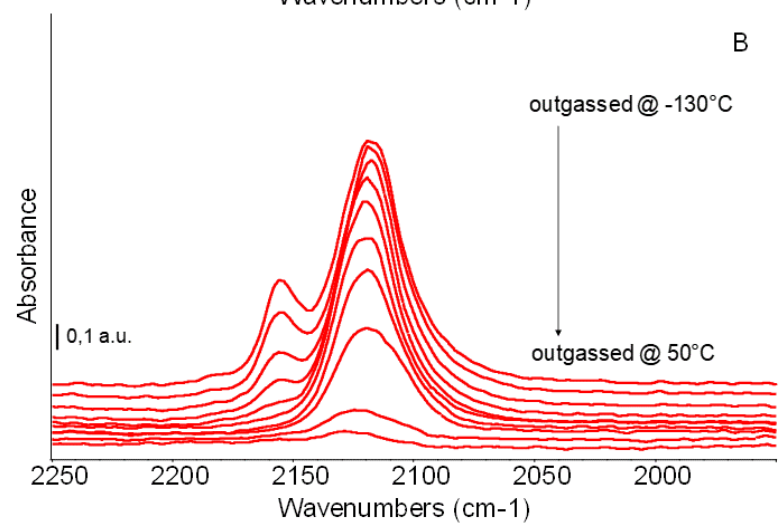

Fig. 3. FT-IR spectra of $\mathrm{CO}$ adsorbed and outgassed at liquid nitrogen temperature and upon warming over $\mathrm{Cu} / \mathrm{SiO}_{2}$ catalyst $\mathrm{A}$. (A) pre reduction step in hydrogen at $500{ }^{\circ} \mathrm{C}$. Inset: deconvolution spectrum $\left(-20 /-10^{\circ} \mathrm{C}\right)$; (B) pre reduction step in hydrogen at $270{ }^{\circ} \mathrm{C}$. The spectrum of catalyst activated surface has been subtracted.

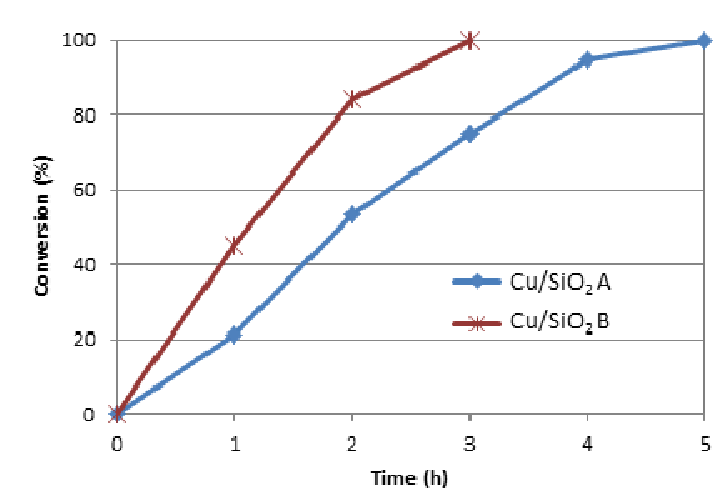

Fig. 4. 3-methylcyclohexanone hydrogenation over two different $\mathrm{Cu} / \mathrm{SiO}_{2}$ catalysts.

3(A), a main band centered at $2120 \mathrm{~cm}^{-1}$ can be detected, showing a shoulder at $2154 \mathrm{~cm}^{-1}$. The latter component can be assigned to some liquid-like $\mathrm{CO}$ and to $\mathrm{CO}$ interacting with the support $\mathrm{OH}$ groups, corresponding to a weak negative band in the subtraction spectrum in the $\mathrm{OH}$ stretching spectral region (spectrum not reported). Possibly, this band overlapped with band due to carbonyl species coordinated over residual $\mathrm{Cu}^{2+}$ ions, characterized by absorptions in the range 2180-2150 $\mathrm{cm}^{-1}[2,20,21]$. Following outgassing this band disappears almost immediately, confirming its assignation to species weakly bound.

The assignment of the complex band at $2120 \mathrm{~cm}^{-1}$ due to $\mathrm{CO}$ interacting with copper centers is widely discussed in the literature. Following results reported by several authors on CO adsorption over $\mathrm{Cu}$-supported catalysts, the strong band centered at $2120 \mathrm{~cm}^{-1}$ asymmetric towards lower frequencies has been assigned to $\mathrm{CO}$ linearly bound to $\mathrm{Cu}^{+}$centers [2,22], but also to $\mathrm{CO}$ coordinated over $\mathrm{Cu}$ metal particles [23]. In particular, for $\mathrm{Cu} / \mathrm{SiO}_{2}$ and $\mathrm{Cu} / \mathrm{TiO}_{2}$ systems, Boccuzzi et al. [23] suggested the attribution of the band at $2128 \mathrm{~cm}^{-1}$ to $\mathrm{CO}$ adsorbed over flat 2D Cu metal particles, strongly interacting with the support, on the basis of the decreased resistance to outgassing. Bands at lower frequencies (2100-2090 $\left.\mathrm{cm}^{-1}\right)$ have been assigned by the same authors to $\mathrm{CO}$ adsorbed over metallic copper in more structured microparticles, exposing steps and well defined facets.

Over alumina supported Cu catalysts, Escribano et al. [24] assigned a strong band at $2115 \mathrm{~cm}^{-1}$ to carbonyls on copper ions or copper zerovalent clusters (which should correspond to the previously mentioned two dimensional metal cluster) and another component centered at $2100 \mathrm{~cm}^{-1}$ and tailing towards lower frequencies to terminal carbonyls on copper zerovalent particles. This assignation has been supported also by the different stability of these species to outgassing: in fact carbonyls on reduced $\mathrm{Cu}$ adsorbs weakly [25]. In the inset in Fig. 3(A) we reported the deconvolution spectra for the band centered at $2120 \mathrm{~cm}^{-1}$, recorded upon warming up to $-20 /-10{ }^{\circ} \mathrm{C}$. Clearly, several components are still detected at 2130, 2121, 2109, $2086 \mathrm{~cm}^{-1}$ and even at lower frequency. Keeping in mind the literature data discussed above, we propose the following assignations: bands in the range $2130-2120 \mathrm{~cm}^{-1}$ characterizing 
mainly carbonyls over $\mathrm{Cu}^{+}$ions and, at a lower extent, a highly dispersed metal phase, strongly interacting with the oxide surface, described as metal cluster [26] only in partial disagreement with Boccuzzi et al. [23], who proposed the assignation of all the bands in this range to zerovalent copper clusters; bands around $2100 \mathrm{~cm}^{-1}$ mainly assigned to carbonyls over zerovalent $\mathrm{Cu}$ clusters, i.e. 2D particles interacting with the support, as reported by Dandekar et al. [2]; components below $2100 \mathrm{~cm}^{-1}$ characterizing CO coordinated over zerovalent copper in structured microparticles. In particular, the detection of a component at $2086 \mathrm{~cm}^{-1}$ is in agreement with the presence of carbonyl species over metal Copper particles, likely exposing well defined crystallographic planes although unusually resistant to outgassing.

The reduction of $\mathrm{Cu} / \mathrm{SiO}_{2} \mathrm{~A}$ in hydrogen at lower temperature $\left(270{ }^{\circ} \mathrm{C}\right)$ leads to the detection of almost the same band pattern (Fig. 3(B)). The increased intensity of the band at 2150 $\mathrm{cm}^{-1}$, assigned mainly to $\mathrm{CO}$ interacting with surface $\mathrm{OHs}$, is in agreement with the pretreatment at lower temperatures which leads to a more hydroxylated surface. The components at low frequency of the main band centred at $2110 \mathrm{~cm}^{-1} \mathrm{ca}$ are less evident. Nevertheless, a component of the absorption below $2000 \mathrm{~cm}^{-1}$ can be detected particularly at the lowest temperatures, assignable to structured $\mathrm{Cu}$ nanoparticles.

In summary, all the analysis agree on the formation of a $\mathrm{CuO}$ phase, easy reducible to $\mathrm{Cu}(0)$ particles or clusters by treatment with hydrogen, as the main species on the catalyst surface. Well formed $\mathrm{Cu}$ cristallites are responsible for the hydrogenation activity observed.

Both catalysts were very effective in the hydrogenation of 3-Me cyclohexanone reaching complete conversion to the corresponding cyclohexanol in few hours at $60{ }^{\circ} \mathrm{C}$ and $1 \mathrm{~atm}$ of $\mathrm{H}_{2}$ (Fig. 4).

To better understand the features affecting the activity of a metal particle it is interesting to evaluate the TOF not only with respect to the total metallic surface area, but also with respect to different coordination sites on the particle. Metal nanoparticles exhibit a variety of facets, edges, and corner sites with different degrees of coordination, which can be crucial for the catalytic activity. The role of different low index $\mathrm{Cu}$ crystal facets in $\mathrm{H}_{2}$ activation has been investigated since a very long time from the theorical point of view by means of quanto mechanical calculations [27-30] but from the experimental point of view the role of different metallic sites has not been deeply investigated.

By assuming that the particles are cubooctahedral in shape is possible to calculate the total number of surface atoms and the fraction of high-coordination sites (HS) and low-coordination sites (LS). The structure sensitivity of the reactions was evaluated considering the TOF for the different atom sites lying on the particles surface.

From the data reported in Table 2 it is apparent that high coordination sites (HS), that is atoms on planar faces, are responsible for the hydrogenation activity. Thus, the ratio between the two TOF is close to $1(0.95)$ whereas the ratio of TOF calculated with respect to low coordination sites (edges) is much different (1.50).
Table 2

Turnover frequencies evaluated after a $1 \mathrm{~h}$ reaction and calculated on different surface atoms.

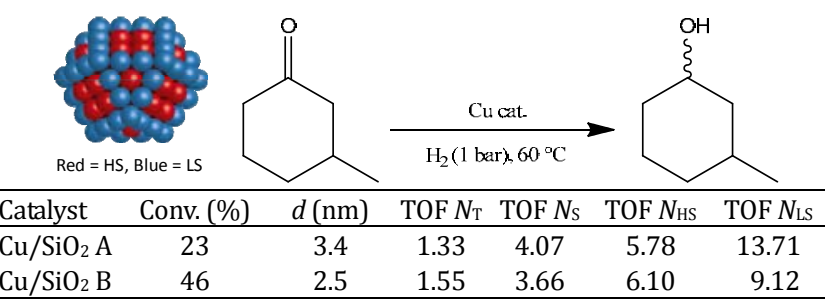

TOF is referred to the total $\mathrm{Cu}$ atoms. The definition of $\mathrm{TOF}_{X}$ has been modified as follows: $\mathrm{TOF}_{x}$ : is the turnover frequency normalized for a specific site $\left(N_{\mathrm{T}}, N_{\mathrm{S}}, N_{\mathrm{HL}}, N_{\mathrm{LS}}\right)$.

To the best of our knowledge this is the first evidence of the determining role of face atoms on the hydrogenation activity of $\mathrm{Cu} / \mathrm{SiO}_{2}$.

The preparation method adopted by our group is quite similar to the ammonia-evaporation method [31] widely used in the hydrogenation of esters, particularly DMO to ethyleneglycol and dimethyladipate to 1,6-hexandiol [32-34]. For this kind of catalysts the presence of both $\mathrm{Cu}(0)$ and $\mathrm{Cu}^{+}$on the pre-reduced material has often been evidenced through XPS although no consensus has been reached on the role of the two species in C-O hydrogenation [35]. According to the work of Ma et al. [36] the catalytic activity was influenced by the amount of $\mathrm{Cu}$ species on the catalyst surface, but $\mathrm{Cu}^{0}$ species may not be the determining factor for this reaction. Thus, a linear dependence of ethyleneglycol space time yield on the surface area of $\mathrm{Cu}^{+}$was found, suggesting that the latter activates the ester group while the former adsorbs $\mathrm{H}_{2}$, best activity and selectivity being observed on the $30 \% \mathrm{Cu}$ catalyst [36]. The presence of $\mathrm{Cu}^{+}$is ascribed to formation of copper phyllosilicate during the preparation of the catalyst that under the pre-treatment conditions used is reduced to $\mathrm{Cu}^{+}$and not to $\mathrm{Cu}(0)$. The presence of a single reduction peak in the TPR profile is ascribed to the reduction of $\mathrm{Cu}$-phyllosilicate to $\mathrm{Cu}^{+}$and of $\mathrm{CuO}$ to $\mathrm{Cu}(0)$ taking place at the same temperature, although some authors propose that the phyllosilicate could be reduced directly to $\mathrm{Cu}(0)$ [37]. Recently a catalyst containing only $\mathrm{Cu}^{0}$ obtained via $\mathrm{Ar}$ plasma sputtering allowed to obtain up to $87 \%$ selectivity to methyl glycolate, the intermediate in the reduction of DMO to EG, with a DMO conversion of $29 \%$. The authors therefore suggest that $\mathrm{Cu}^{+}$is determining in promoting complete hydrogenation to EG [38].

In the case of catalysts prepared by the chemisorption-hydrolysis method the presence of $\mathrm{Cu}^{+}$or phyllosilicate on the surface of the catalysts is uncertain. For the sake of comparison we prepared a sample by using silica $\mathrm{A}$ and the $\mathrm{AE}$ method by following the procedure described by Dong et al. [37] but lowering the $\mathrm{Cu}$ loading to $8 \%$. We compared the textural properties, TPR profiles and the hydrogenation activity of this sample, hereafter called $\mathrm{Cu} / \mathrm{SiO}_{2} \mathrm{C}$, with the catalysts prepared by $\mathrm{CH}$.

TPR profiles for all the catalysts (Fig. 5) show a single very sharp peak with a maximum at $230{ }^{\circ} \mathrm{C}$ for catalyst A and slightly higher for the other two. In particular as both $\mathrm{Cu} / \mathrm{SiO}_{2} \mathrm{~A}$ and 


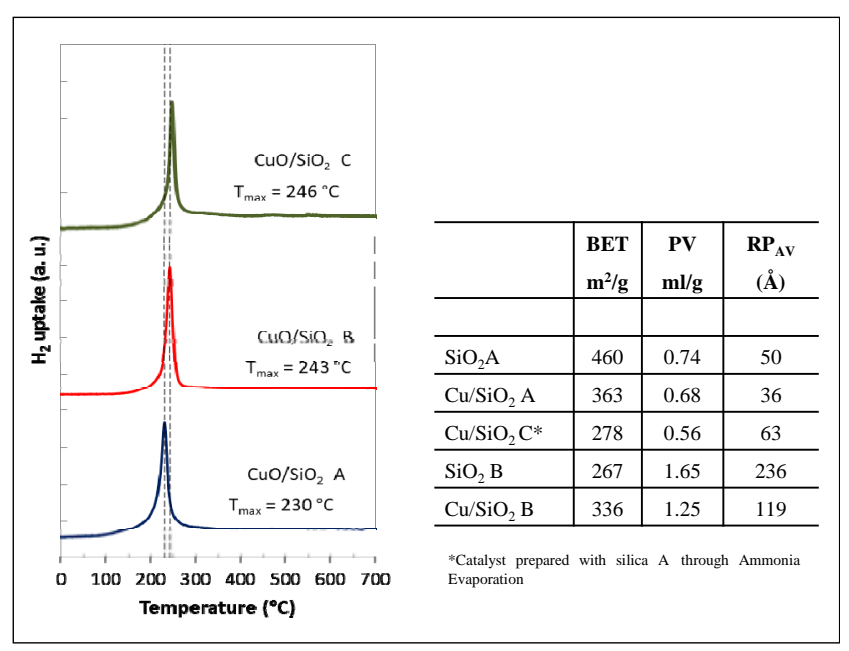

Fig. 5. TPR profiles and textural properties of different $\mathrm{Cu} / \mathrm{SiO}_{2}$ catalysts.

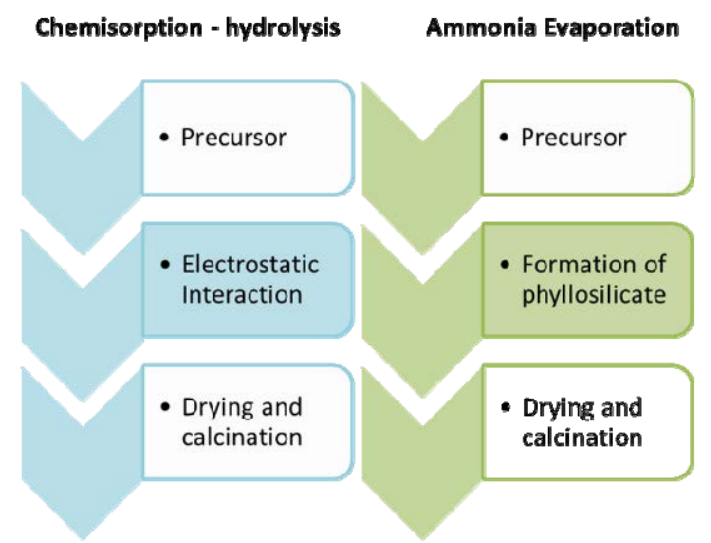

Fig. 6. Comparison of the main steps in the preparation of $\mathrm{Cu} / \mathrm{SiO}_{2}$ catalysts from $\left[\mathrm{Cu}\left(\mathrm{NH}_{3}\right)_{4}\right]^{2+}$ solutions.

$\mathrm{Cu} / \mathrm{SiO}_{2} \mathrm{C}$ are prepared on the same support and with the same $\mathrm{Cu}$ loading the preparation method may give account of the difference in T. As far as textural features are concerned we can observe that the lowering of surface area is more significant for the catalyst prepared by AE.

On the other hand, a dramatic difference was observed in the hydrogenation reaction of 3-methyl-cyclohexanone. The catalyst prepared by $\mathrm{AE}$ was found to be almost inactive, conversion after $24 \mathrm{~h}$ being limited to $25 \%$ under the experimental conditions used for the other two catalysts (Table 2).

This unequivocally witnesses the deep difference between the two systems due to the significative formation of phyllosilicate for the ammonia evaporation system, as shown by several authors (Fig.6).

\section{Conclusions}

In conclusion, we have shown that the activity of $\mathrm{Cu} / \mathrm{SiO}_{2}$ catalyst prepared by $\mathrm{CH}$ in the hydrogenation reaction of ketone groups is strongly linked to the metal particle morphology in turn determined by the preparation method, as was already observed for the $\mathrm{Cu} / \mathrm{TiO}_{2}$ systems in the hydrogenation of conjugated dienes [15].

Thus, hydrogenation of 3- methyl-cyclohexanone strongly depends on the presence of high coordination sites located on the faces of the metal particle that appears well formed in cuboctahedral geometry.

On the contrary, catalysts prepared by AE although easily reducible as shown by TPR and very well dispersed as shown by TEM [37] are not able to hydrogenate this substrate under the same conditions $\left(1 \mathrm{~atm} \mathrm{H}_{2}, 60^{\circ} \mathrm{C}\right)$ probably due to the different morphology of the particles.

\section{References}

[1] C. L. Thomas, Catalytic Processes and Proven Catalysts, Academic Press, New York, 1970.

[2] A. Dandekar, M. A. Vannice, J. Catal., 1998, 178, 621-639.

[3] D. Liu, D. Zemlyanov, T. Wu, R. J. Lobo-Lapidus, J. A. Dumesic, J. T. Miller, C. L. Marshall, J. Catal., 2013, 299, 336-345.

[4] V. Z. Fridman, A. A. Davydov, J. Catal., 2000, 195, 20-30.

[5] N. P. Tangale, P. S. Niphadkar, S. S. Deshpande, P. N. Joshi, Appl. Catal. A, 2013, 467, 421-429.

[6] M. Boudart, Adv. Catal., 1969, 20, 153-66.

[7] R. S. Rao, A. B. Walters, M. A. Vannice, J. Phys. Chem. B, 2005, 109, 2086-2092.

[8] A. I. Tripol'skii, N. V. Pavalenko, G. I. Golodets, Kinet. Catal., 1985, 26, 1131-1135.

[9] R. van den Berg, G. Prieto, G. Korpershoek, L. I. van der Wal, A. J. van Bunningen, S. Lægsgaard-Jørgensen, P. E. de Jongh, K. P. de Jong, Nat. Commun., 2016, 7, 13057.

[10] M. J. Climent, A. Corma, S. Iborra, Green Chem., 2014, 16, 516-547.

[11] S. Chen, R. Wojcieszak, F. Dumeignil, E. Marceau, S. Royer, Chem. Rev., 2018, 118, 11023-11117.

[12] C. Wen, Y. Cui, A. Yin, K. Fan, W.-L. Dai, ChemCatChem, 2013, 5, 138-141.

[13] R. E. Benfield, J. Chem. Soc., Faraday Trans., 1992, 88, 1107-1110.

[14] K. Mori, T. Hara, T. Mizugaki, K. Ebitani, K. Kaneda, J. Am. Chem. Soc., 2004, 126, 10657-10666.

[15] F. Boccuzzi, A. Chiorino, M. Gargano, N. Ravasio, J. Catal., 1997, $165,140-149$.

[16] N. Scotti, M. Dangate, A. Gervasini, C. Evangelisti, N. Ravasio, F. Zaccheria, ACS Catal., 2014, 4, 2818-2826.

[17] C. E. Chan-Thaw, M. Marelli, R. Psaro, N. Ravasio, F. Zaccheria, RSC Adv., 2013, 3, 1302-1306.

[18] F. Zaccheria, N. Scotti , M. Marelli , R. Psaro, N. Ravasio, Dalton Trans., 2013, 42, 1319-1327.

[19] F. Zaccheria, N. Ravasio, M. Ercoli, P. Allegrini, Tetrahedron Lett., 2005, 46, 7743-7745.

[20] A. Gervasini, M. Manzoli, G. Martra, A. Ponti, N. Ravasio, L. Sordelli, F. Zaccheria, J. Phys. Chem. B, 2006, 110, 7851-7861.

[21] G. Busca, J. Mol. Catal., 1987, 43, 225-236.

[22] N. Y. Topsoe, H. Topsoe, J. Mol. Catal. A, 1999, 141, 95-105.

[23] F. Boccuzzi, S. Coluccia, G. Martra, N. Ravasio, J. Catal., 1999, 184, 316-326.

[24] V. Sanchez-Escribano, L. Arrighi, P. Riani, R. Marazza, G. Busca, Langmuir, 2006, 22, 9214-9219.

[25] E. Finocchio, I. Rossetti, G. Ramis, Int. J. Hydrogen Energy, 2013, 38, 3213-3225.

[26] I. Rossetti, J. Lasso, V. Nichele, M. Signoretto, E. Finocchio, G. Ramis, A. Di Michele, Appl. Catal. B, 2014, 150-151, 257-267. 


\title{
Graphical Abstract
}

Chin. J. Catal., 2019, 40: 1788-1794 doi: S1872-2067(19)63392-9

Some insight on the structure/activity relationship of metal nanoparticles in $\mathrm{Cu} / \mathrm{SiO}_{2}$ catalysts

Nicola Scotti, Elisabetta Finocchio, Claudio Evangelisti, Marcello Marelli, Rinaldo Psaro, Nicoletta Ravasio *, Federica Zaccheria CNR ISTM, Milano, Italy; University of Genoa, Genova, Italy

The activity of $\mathrm{Cu} / \mathrm{SiO}_{2}$ catalysts in the hydrogenation of 3-methyl-cyclohexanone was found to be linked to high coordination sites on the metal $\mathrm{Cu}$ particle, whereas acidic sites are represented by defective, low coordination sites.

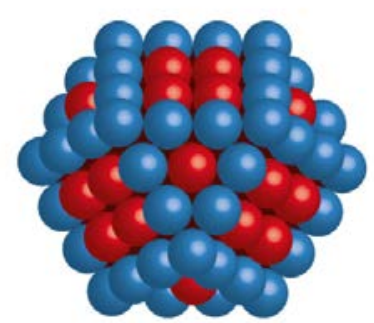

Blue atoms $=$ Lewis acid sites

Red atoms $=$ Hydrogenation sites
[27] A. R. Gregory, A. Gelb, R. Silbey, Surf. Sci., 1978, 74, 497-523.

[28] H. A. Michelsen, D. J. Auerbach, J. Chem. Phys., 1991, 94, 7502-7520.

[29] G. Kyriakou, M. B. Boucher, A. D. Jewell, E. A. Lewis, T. J. Lawton, A. E. Baber, H. L. Tierney, M. Flytzani-Stephanopoulos, E. C. H. Sykes, Science, 2012, 335, 1209-1212.

[30] L. Álvarez-Falcón, F. Viñes, A. Notario-Estévez, F. Illas, Surf. Sci,, 2016, 646, 221-229.

[31] L.-F. Chen, P.-J. Guo, M.-H. Qiao, S.-R. Yan, H.-X. Li, W. Shen, H.-L. Xua, K.-N. Fan, J. Catal., 2008, 257, 172-180.

[32] X. Ma, H. Chi, H. Yue, Y. Zhao, Y. Xu, J. Lv, S. Wang, J. Gong, AIChE J., 2013, 59, 2530-2539.
[33] S. Li, Y. Wang, J. Zhang, S. Wang, Y. Xu, Y. Zhao, X. Ma, Ind. Eng. Chem. Res., 2015, 54, 1243-1250.

[34] Y. Zhao, Z. Guo, H. Zhang, B. Peng, Y. Xu, Y. Wang, J. Zhang, Y. Xu, S. Wang, X. Ma, J. Catal., 2018, 357, 223-237.

[35] Y. Wang, Y. Shen, Y. Zhao, J. Lv, S. Wang, X Ma, ACS Catal., 2015, 5, 6200-6208.

[36] Y. Zhao, S. Li, Y. Wang, B. Shan, J. Zhang, S. Wang, X. Ma, Chem. Eng. J., 2017, 313, 759-768.

[37] X. Dong, X. Ma, H. Xu, Q. Ge, Catal. Sci. Technol., 2016, 6, 4151-4158.

[38] J. Sun, J. Yu, F. Meng, Y. Sun, Q. Ma, X. Wei, N. Tsubaki, Sci. Adv., 2018, 4, eaau3275.

\section{铜/二氧化硅催化剂中金属纳米粒子构性关系的一些认识}

\author{
Nicola Scotti ${ }^{\text {a }}$, Elisabetta Finocchio ${ }^{\text {b }}$, Claudio Evangelisti ${ }^{a}$, Marcello Marelli $^{\text {a }}$, Rinaldo Psaro ${ }^{\text {a }}$, \\ Nicoletta Ravasio $^{\mathrm{a}, *}$, Federica Zaccheria ${ }^{\mathrm{a}}$ \\ a国家研究委员会演技中心, 分子科学与技术研究所, 催化实验室, 20133米兰, 意大利 \\ 热那亚大学, 理工学院, 土木工程与环境化学系(DICCA), 16145热那亚, 意大利
}

摘要: 考察了化学吸附水解法制备的两种铜/二氧化硅催化剂上3-甲基环已酮加氢反应活性. 发现两种催化剂在 $60{ }^{\circ} \mathrm{C}$ 和 1 bar $\mathrm{H}_{2}$ 下催化活性非常高. 吸附CO红外光谱和透电镜结果表明, 催化剂中存在结晶良好的铜颗粒. 通过假设一个立方八面 体模型, 我们可以证明加氢活性与金属颗粒上的高配位点有关. 本文还与蒸氨法制备的样品进行了比较, 发现在相同的实 验条件下, 蒸氨法样品在加氢反应中没有活性.

关键词: 铜颗粒; 金属粒子形态; Lewis酸位; 加氢; 双功能催化剂

收稿日期: 2019-03-28. 接受日期: 2019-05-08. 出版日期: 2019-11-05.

*通讯联系人. 电子信箱: n.ravasio@istm.cnr.it

本文的电子版全文由Elsevier出版社在ScienceDirect上出版(http://www.sciencedirect.com/science/journal/18722067). 